\title{
Functional changes of the ulnar nerve in leprosy patients following neurolysis
}

\author{
J W BRANDSMA, W A H NUGTEREN, J B ANDERSEN \\ \& B NAAFS \\ All Africa Leprosy and Rehabilitation Training Centre (ALERT), \\ PO Box 165 Addis Ababa, Ethiopia
}

Received for publication 4 May 1982

\begin{abstract}
Summary A functional follow up of ulnar neurolysis is presented. Functional changes have been related to the indication for neurolysis. Motor function of $52 \%$ of the nerves was improved in the group in which neurolysis was performed to facilitate nerve recovery. The rate of functional improvement appears also to depend on the duration of the recorded nerve damage and the classification of leprosy. Functional changes in the operated nerve have been compared with the non-operated nerve in cases of bilateral ulnar nerve involvement.
\end{abstract}

\section{Introduction}

Prevention of recurrent neuritis or the relief of intractable nerve pain used to be the main indications for ulnar neurolysis in leprosy. It has been reported ${ }^{1}$ that the need for neurolysis for these indications has decreased considerably since the introduction of clofazimine and thalidomide.

Most authors seem to agree that neurolysis is very helpful in the relief of nerve pain and that, whatever surgical technique is employed, neurolysis has no harmful effect on nerve function. Few authors have defined or quantified functional changes of the ulnar nerve following neurolysis. A nerve index ${ }^{2}$ has been developed, using voluntary muscle testing, sensory testing and motor nerve conduction velocities, to follow patients with recent nerve damage and to evaluate possible functional benefits of nerve surgery. In one study ${ }^{3}$ this nerve index was used to study patients who had ulnar neurolysis, comparing the results with the contralateral affected nerve.

The indications and results of ulnar neurolysis in recent publications are summarized in Table 1. This present study gives the functional changes in 
Table 1. Neurolysis in leprosy

\begin{tabular}{|c|c|c|c|c|c|c|c|c|c|c|c|c|c|}
\hline \multirow[b]{2}{*}{ Author (year) } & \multirow[b]{2}{*}{$\begin{array}{c}\text { Operated } \\
\text { nerves }\end{array}$} & \multirow[b]{2}{*}{ Ulnar } & \multicolumn{4}{|c|}{ Classification } & \multicolumn{3}{|c|}{ Indication } & \multicolumn{4}{|c|}{ Functional results } \\
\hline & & & Median & $\mathrm{T}$ & B & $\mathrm{L} \quad \mathrm{F}$ & Pain relief & $\begin{array}{c}\text { Functional } \\
\text { recovery }\end{array}$ & Pain relief & Improved & Unchanged & Deteriorated & \\
\hline Callaway $^{4}(1964)$ & 100 & $\mathrm{X}$ & $\mathrm{X}$ & \multicolumn{3}{|c|}{ not given } & 81 & $\mathrm{a}$ & $99 \%$ & $30 \%$ & & & \\
\hline $\operatorname{Parikh}^{5}(1968)$ & 17 & 13 & 4 & 10 & 1 & 2 & $\mathrm{X}$ & $\mathrm{X}$ & $77 \%$ & $16 \%$ & $27 \%$ & $18 \%$ & \\
\hline \multirow[t]{4}{*}{ Vaidyanathan ${ }^{6}(1968)$} & 88 & 88 & 0 & 34 & 9 & 36 & $\mathrm{X}$ & $\mathrm{X}$ & $97 \%$ motor & $71 \%$ & $29 \%$ & & $\mathrm{~b}$ \\
\hline & & & & & & & & & sens. & $50 \%$ & $48 \%$ & $2 \%$ & \\
\hline & & & & & & & & & motor & $17 \%$ & $83 \%$ & & $\mathrm{c}$ \\
\hline & & & & & & & & & sens. & $14 \%$ & $86 \%$ & & \\
\hline \multirow[t]{2}{*}{$\operatorname{Said}^{7}(1972)$} & 38 & 32 & 6 & 30 & & 6 & $\mathrm{X}$ & & $91 \%$ motor & $58 \%$ & & & \\
\hline & & & & & & & & & sens. & $46 \%$ & & & \\
\hline \multirow[t]{2}{*}{ Palande $^{8}(1973)$} & 23 & 23 & 0 & 8 & 9 & 6 & $\mathrm{X}$ & & $100 \%$ motor & $57 \%$ & & & $\mathrm{~d}$ \\
\hline & & & & & & & & & sens. & $13 \%$ & & & \\
\hline Carayon $^{9}(1974)$ & 70 & 70 & 0 & & $\mathrm{t}$ gi & ven & & $\mathrm{X}$ & & $71 \%$ & $29 \%$ & & $\mathrm{e}$ \\
\hline Enna $^{1}(1974)$ & 103 & 103 & 0 & 'leprc & oma & tous' & $\mathrm{X}$ & & $55 \%$ & & & & \\
\hline Oomen $^{10}(1979)$ & 16 & 16 & 0 & 4 & 5 & 5 & $\mathrm{X}$ & $\mathrm{X}$ & & $94 \%$ & & $6 \%$ & \\
\hline
\end{tabular}

Notes:

${ }^{\mathrm{a}}$ Indication: prevent progressive paralysis.

${ }^{\mathrm{b}}$ Functional loss less than 3 months.

${ }^{\mathbf{c}}$ Functional loss more than 3 months.

${ }^{\mathrm{d}}$ Recovery related to type and duration of involvement.

${ }^{\mathrm{e}}$ Duration functional loss less than 6 months. 
motor and sensory fibre functions in patients operated upon between 1972 and 1979 at the All Africa Leprosy and Rehabilitation Training Centre (ALERT), Addis Ababa, Ethiopia.

\section{Method and material}

On 106 patients a total of 129 ulnar neurolyses were performed. The different indications for neurolysis are given in Table 2. The number of indications is higher than the number of nerves operated because of 17 double indications. We were able to assess the results of 100 neurolyses in patients who had at least 1 year of post-operative follow-up. However, if major functional changes had occurred before the first year following surgery and the patient did not have a follow up of a year then the patient was also included. Twenty patients had bilateral ulnar neurolysis.

The assessment technique used in evaluating motor function recovery was the voluntary muscle testing as described ${ }^{11}$ for leprosy patients.

The same grading system for muscle strength was used as reported by the Medical Research Council. ${ }^{12}$

The grades for abduction of the little finger and the abduction of the index finger were totalled. A normal function of the ulnar nerve would thus give a score of 10 . When the post-operative muscle score was more than 8 the sensation was reviewed from the record. In our experience sensation is not likely to be present when there is still considerable motor involvement.

\section{Surgical technique and findings}

All cases for neurolysis in this series were referred from the physicians. There was no bias from the surgeons as to which nerve to operate upon and which to leave under medication alone. The majority of the operations were performed without tourniquet, only towards the end of the series were the operations performed in a bloodless field, thus allowing a detailed recording of the findings.

Table 2. Indication for surgery related to classification

\begin{tabular}{lcccccc}
\hline & $\begin{array}{c}\text { Pain } \\
\text { relief }\end{array}$ & $\begin{array}{c}\text { Functional } \\
\text { improvement }\end{array}$ & Abscess & $\begin{array}{c}\text { Not } \\
\text { recorded }\end{array}$ & $\begin{array}{c}\text { Number of } \\
\text { indications }\end{array}$ & $\begin{array}{c}\text { Number of } \\
\text { Patients }\end{array}$ \\
\hline (B)T & 11 & 40 & 5 & 2 & 58 & 45 \\
B & 4 & 3 & 0 & 0 & 7 & 6 \\
(B)L & 42 & 32 & 1 & 6 & 18 & 55 \\
& 57 & 75 & 6 & 8 & 146 & 106 \\
\hline
\end{tabular}

Note: Table gives the indications for all operated nerves. 
In all cases the nerve was exposed from the exit of the axilla to the entry into the depth of the forearm. In some of the earlier cases a regular anteposition of the nerve was performed, sacrificing the feeder vessels. In the latter part of the series these vessels were carefully preserved. Possible adhesions were freed, and a longitudinal epineurotomy was performed, as far as possible avoiding damage to the epineurial vessels. In the latter part of the series the tissue surrounding the feeder vessels and the nerve was removed. The ulnar intermuscular septum was invariably resected, thus preventing any kinking of the nerve and allowing free play when extending or flexing the elbow.

The epineurium was found to be of varying thickness and the fascicles were typically swollen and yellow. In some cases, notably these of long-standing nerve damage, where functional recovery was not expected, fascicular structure could not be detected.

In most cases the feeder vessels were of normal calibre but, in some, particularly those of long-standing nerve damage, they were engorged, indicating a venous obstruction outside the nerve. The epineurial vessels were in most cases engorged, although in some cases they were thin, even invisible, indicating endoneurial over-pressure.

At the end of operation both the engorged feeder vessels and epineurial vessels assumed normal calibre. Where the epineurial vessels were either thin of invisible, they usually assumed normal calibre. However, in a few cases the nerve became thinner during the operation.

\section{Results}

Motor nerve function was considered to have improved or deteriorated when the total muscle grading score had changed two or more points.

Table 3 shows the relationship between the postoperative ulnar motor changes to the pre-operative duration of functional loss. It was not always possible to determine exactly the onset of motor nerve involvement from the records and often the history had to be relied on.

None of the patients with a motor deficit of more than 6 months recovered fully from total paralysis and the average improvement in long-standing palsies was only 3 points.

Table 4 gives the motor function changes per indication and classification. The data in the table suggest that greater improvement is found in (B)T nerves.

Table 5 shows the degree of improvement in muscle strength of the 39 nerves that improved. It will be seen that only 2 nerves recovered their motor function completely from total nerve function loss, whereas 10 nerves recovered completely from partial nerve function loss.

Six patients, 2T, 3BT and $1 \mathrm{BL}$ patient had nerve abscesses. Three nerves remained without function postoperatively, 1 deteriorated and 2 improved. 
Table 3. Motor function changes related to pre-operative duration of muscle paresis/paralysis

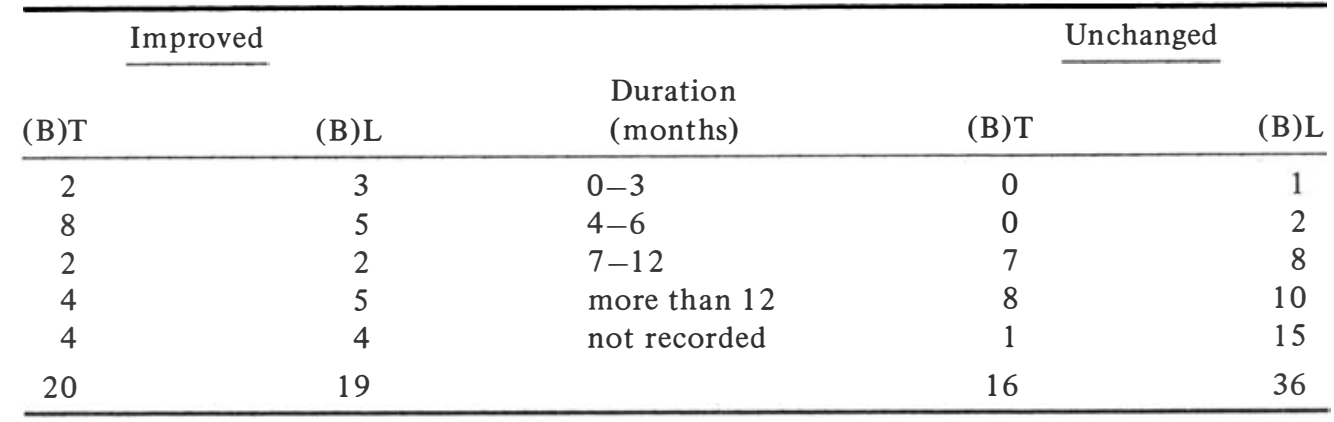

Notes: The few patients classified 'borderline' have been included in this table under (B)T. Compare with Table 4. Two (B)L patients that remained unchanged have been omitted from this table because there was no functional loss pre-operatively.

Table 4. Changes in motor nerve function

\begin{tabular}{lcclr}
\hline & Improved & Unchanged & Deteriorated \\
\cline { 2 - 5 } Indication-functional recovery & & & & \\
(B)T & $16(55 \%)$ & $12(41 \%)$ & $1(4 \%)$ & \\
B & $3(100 \%)$ & 0 & 0 & \\
(B)L & $11(42 \%)$ & $14(54 \%)$ & $1(4 \%)$ & \\
$\quad$ Total & $30(52 \%)$ & $26(45 \%)$ & $2(3 \%)$ & 58 \\
Other indications & & & & \\
(B)T & $1(17 \%)$ & $3(50 \%)$ & $2(33 \%)$ & \\
B & 0 & $1(50 \%)$ & $1(50 \%)$ & \\
(B)L & $8(24 \%)$ & $24(70 \%)$ & $2(6 \%)$ & \\
$\quad$ Total & $9(21 \%)$ & $28(67 \%)$ & $5(12 \%)$ & 42 \\
$\quad$ Overall totals & 39 & 54 & 7 & 100 \\
\hline
\end{tabular}

Table 5. Degree of improvement in motor nerve function

\begin{tabular}{ccccccr}
\hline Pre-operative & \multicolumn{2}{l}{ Post-operative function } & & & \\
\cline { 2 - 7 } Function & $2-3$ & $4-5$ & $6-7$ & $8-9$ & 10 & Total \\
\hline $0-1$ & 6 & 4 & 3 & 3 & 2 & 18 \\
$2-3$ & 0 & 2 & 1 & 1 & 1 & 5 \\
$4-5$ & 0 & 0 & 4 & 1 & 1 & 6 \\
$6-7$ & 0 & 0 & 0 & 2 & 5 & 7 \\
$8-9$ & 0 & 0 & 0 & 0 & 3 & 3 \\
Total & 6 & 6 & 8 & 7 & 12 & 39 \\
\hline
\end{tabular}

There were 7 nerves that deteriorated but only in one case could the deterioration be attributed to the surgery. In this case there was immediate postoperative functional loss. In the remaining 6 patients other nerves also deteriorated. In these cases chronic ery thema nodosum leprosum, DDS resistance and discontinuation of treatment were possible contributing factors. 
Table 6. Functional changes in operated and contralateral affected nerves

\begin{tabular}{|c|c|c|c|c|c|c|c|c|}
\hline & \multicolumn{4}{|c|}{ All contralateral affected nerves ${ }^{*}$} & \multicolumn{4}{|c|}{ Comparable nerve damage contralateral $^{\dagger}$} \\
\hline & \multirow{2}{*}{$\frac{\text { Operated }}{\text { No }}$} & \multicolumn{3}{|c|}{ Non-operated } & \multicolumn{2}{|l|}{ Operated } & \multicolumn{2}{|c|}{ Non-operated } \\
\hline & & Improved & Unchanged & Deteriorated & No & Improved & Unchans & Deteriorated \\
\hline Improved & 18 & 13 & 4 & 1 & 9 & 6 & 2 & 1 \\
\hline Unchanged & 23 & 8 & 14 & 1 & 10 & 3 & 7 & \\
\hline \multirow[t]{2}{*}{ Deteriorated } & 2 & & 2 & & 1 & & 1 & \\
\hline & 43 & 21 & 20 & 2 & 20 & 9 & 10 & 1 \\
\hline
\end{tabular}

* All nerves irrespective of indication for surgery and difference in nerve damage

${ }^{\dagger}$ Nerves in which functional recovery was expected. Comparable nerve damage: not more than two points difference on totalled VMT score

There were 43 patients who had bilateral ulnar nerve damage and who only had one nerve operated upon. In Table 6 we have compared the results of the operated nerve with the non-operated contralateral affected nerve. The data on sensory changes were reviewed from the record when the post operative muscle score was more than 8 . From Table 5 it will be seen that there were 19 nerves which had recovered this muscle strength. Of these only 5 had recovered sensation when tested with bristle no 5 .

Pain relief was achieved in an estimated $80-90 \%$ of the patients.

\section{Discussion}

Motor nerve conduction of both ulnar nerves was assessed regularly in all patients included in this study. We did not analyse these results separately as we soon realized that muscle testing scores alone gave us comparable information. In experienced hands manual muscle testing is a very useful and objective test to evaluate motor nerve function.

Our findings confirm other reports that neurolysis does not harm the nerve. The case notes revealed that prednisolone dependency was a problem in many patients, especially in (B)L patients. We noticed that on occasions prednisolone was given to the patient merely for nerve pain in which the nerve function assessments showed that the nerve was already dead or that decreased nerve function had persisted for many years. This was especially so in the group where neurolysis was performed for pain relief. Progress notes in the patient files also showed that many patients had asked for prednisolone. The problem of steroid dependency in lepromatous leprosy patients has been previously reported. ${ }^{13}$ It suggests that prednisolone could be reduced and stopped after these patients were given clofazimine. It seems from this observation that the physician should be very cautious in prescribing prednisolone and that he should only prescribe this drug when there are indications of an active neuritis.

Unfortunately it was not possible to relate the results of neurolysis to antileprosy and antineuritis treatment. In the early 'seventies patients were still 
taken off DDS treatment during neuritis, and when DDS treatment was initiated it was started with a low dose which was gradually increased to $300 \mathrm{mg}$ weekly. As from 1974 patients were given DDS $100 \mathrm{mg}$ daily and DDS treatment was not discontinued when patients developed neuritis. Many patients, in addition to DDS treatment, received clofazimine for varying periods and in differing dosages. In the management of neuritis the picture was the same where different courses with different dosages were given to all patients. As might be expected improvement is greater when neurolysis is undertaken when functional results are anticipated and (B)T nerves do better than (B) L nerves.

More careful studies are needed to determine possible functional benefits of nerve surgery. This study also clearly highlights the importance of careful recording. Future studies in our opinion should include details such as: (a) duration of nerve function loss from history or from record; (b) presence of muscle atrophy as an indication of the duration of loss of muscle function; (c) classification of the disease, type of reaction and bacteriological and morphological index (BI and MI); (d) medication: both antileprosy and immune suppressive drugs; (e) indication for surgery, surgical technique and findings on surgery; and (f) quantification of nerve function changes pre- and postoperatively. From this study it is not possible to determine if neurolysis will give better results than medical treatment alone. However, there do not seem to be important differences between the operated nerve and the contralateral affected nerve. Although the neurolyses reported in this study were not performed in a controlled trial we have attempted to relate the nerve function changes to duration of the nerve damage, indication for neurolysis and classification of the leprosy.

\section{References}

${ }^{1}$ Enna CD, Jacobsen RR. A clinical assessment of neurolysis for leprous involvement of the ulnar nerve. Int J Lepr 1974; 42: 162-4.

2 Naafs B, Van Droogenbroeck JBA. Decompression des nevrites reactionelles dans la lepre: Justification physiophatologique et methodes objectives pour en apprecier les resultats. Med Trop 1977; 37: 763-70.

${ }^{3}$ Van Droogenbroeck JBA, Naafs B. Etude comparative d'une serie de nerfs lepreux decomprimés chirurgicalement par rapport aux nerfs controlateraux non operés. Med Trop 1977; 37: 771-6.

${ }^{4}$ Callaway JC, Fite GL, Riordan DC. Ulnar and median neuritis due to leprosy. Int $J$ Lepr 1964; 32: 285-91.

5 Parikh AC, Ganapati R, Kothare KB, Divekar SC. Decompression of the ulnar and median nerves in leprous neuritis. Lepr Rev 1968; 39: 143-6.

${ }^{6}$ Vaidyanathan EP, Vaidyanathan SI. Treatment of ulnar neuritis and early ulnar paralysis. Lepr Rev 1968; 39: 217-22.

7 Said GZ, Zokdy A, El-Akkad In. External and internal neurolysis of the ulnar and median nerves in leprous neuritis Lepr Rev 1973; 44: 36-43. 
8 Palande DD, Kumbakonam MS. A review of twenty-three operations on the ulnar nerve in leprous neuritis. J Bone Jt Surg 1973; 55A: 1457-64.

9 Carayon AE. The value of peripheral neurosurgical procedures in neuritis In: Enna CD, McDowell F eds. Surgical rehabilitation in leprosy. Baltimore: Williams and Wilkins, 1974:37-49.

10 Oomen OK. Nerve decompression by medial epicondylectomy of the humerus and a method of assessing muscle power status by totalling the muscle grading. Lepr Ind $1979 ; 51: 330-40$.

11 Brandsma JW. Basic nerve function assessment in leprosy patients. Lepr Rev 1981; 52: $161-70$

12 Medical Research Council war memorandum. Aids to the investigation of peripheral nerve in juries (memo no. 7), 2nd edn. London: HMSO, 1962.

${ }^{13}$ Imkamp FMJHA. A treatment of corticosteroid-dependent lepromatous patients in persistent erythema nodosum leprosum. A clinical evaluation of G. 30320 (B663). Lepr Rev 1968; 119-25. 